
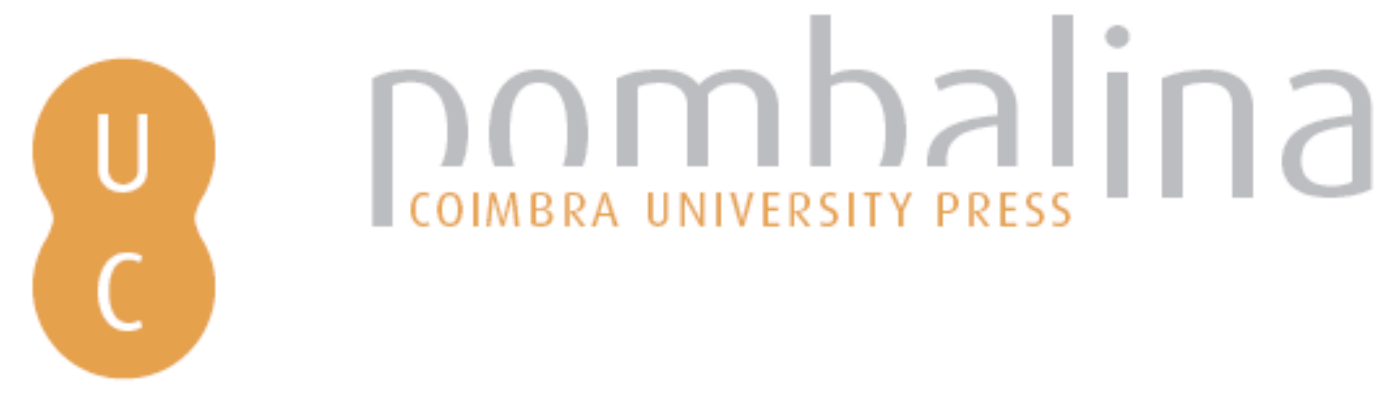

\title{
O estado da arte do ensino significativo da geologia: a teoria epistemológica da Educação Profissionalizante associada à geodiversidade
}

\begin{tabular}{ll} 
Autor(es): & $\begin{array}{l}\text { Nascimento, Magnólia; Silva, Pedro Douglas; Louzada, Cassiano; } \\
\text { Tonelli, Elizângela }\end{array}$ \\
Publicado por: & $\begin{array}{l}\text { Imprensa da Universidade de Coimbra; Laboratório de Radioactividade } \\
\text { Natural da Universidade de Coimbra }\end{array}$ \\
$\begin{array}{l}\text { URL } \\
\text { persistente: }\end{array}$ & URI:http://hdl.handle.net/10316.2/36308 \\
DOI: & DOI:http://dx.doi.org/10.14195/978-989-26-1009-2_19 \\
Accessed : & 26-Apr-2023 15:12:58 \\
\hline
\end{tabular}

A navegação consulta e descarregamento dos títulos inseridos nas Bibliotecas Digitais UC Digitalis, UC Pombalina e UC Impactum, pressupõem a aceitação plena e sem reservas dos Termos e Condições de Uso destas Bibliotecas Digitais, disponíveis em https://digitalis.uc.pt/pt-pt/termos.

Conforme exposto nos referidos Termos e Condições de Uso, o descarregamento de títulos de acesso restrito requer uma licença válida de autorização devendo o utilizador aceder ao(s) documento(s) a partir de um endereço de IP da instituição detentora da supramencionada licença.

Ao utilizador é apenas permitido o descarregamento para uso pessoal, pelo que o emprego do(s) título(s) descarregado(s) para outro fim, designadamente comercial, carece de autorização do respetivo autor ou editor da obra.

Na medida em que todas as obras da UC Digitalis se encontram protegidas pelo Código do Direito de Autor e Direitos Conexos e demais legislação aplicável, toda a cópia, parcial ou total, deste documento, nos casos em que é legalmente admitida, deverá conter ou fazer-se acompanhar por este aviso.

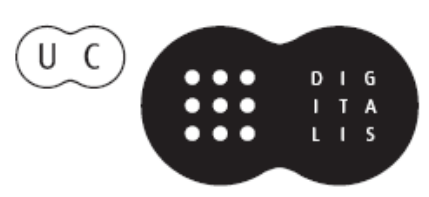




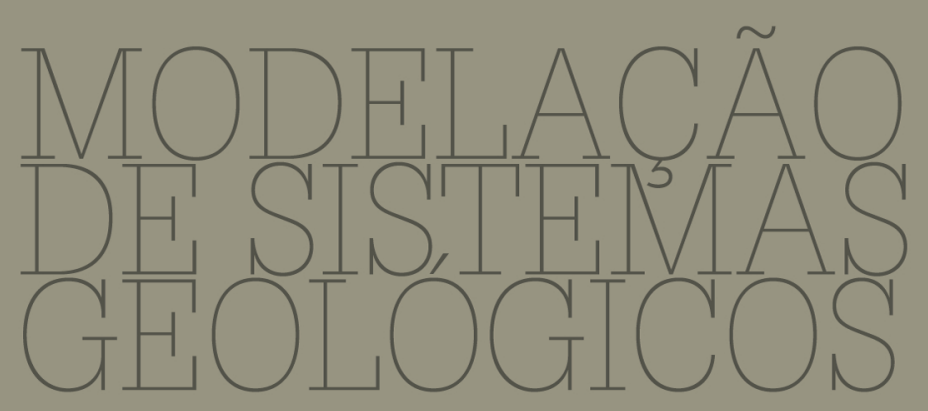

Homenagem ao Professor Doutor Manuel Maria Godinho

L.J.P.F. Neves, A.J.S.C. Pereira,

C.S.R. Gomes, L.C.G. Pereira,

A.O. TAVARES

IMPRENSA DA UNIVERSIDADE DE COIMBRA

CoImBra University Press 


\title{
MODELAÇÃO \\ DE SISTEMAS \\ GEOLÓGICOS
}

Homenagem ao Professor Manuel Maria Godinho

\section{O Estado da Arte do ensino significativo da geologia: A teoria epistemológica da Educação Profissionalizante associada à Geodiversidade}

\author{
Magnólia Nascimento ; Pedro Douglas Silva ${ }^{2}$; Cassiano Louzada ${ }^{3}$; Elizângela \\ Tonelli $^{4}$ \\ ${ }^{1}$ Instituto Federal de Ciência e Tecnologia do Ceará (IFCE), Campus de Fortaleza, BRASIL. \\ ${ }^{2}$ Pós - Graduando pela Universidade de Coimbra (UC), em Engenharia Geológica e de Minas, \\ Departamento de Ciências da Terra. / (pedrosalguod@ig.com.br). \\ ${ }^{3,4}$ Instituto Federal de Ciência e Tecnologia do Espírito Santo (IFES), Campus de Cachoeiro de \\ Itapemirim - ES, Brasil.
}

Palavras-chave: PROEJA - FIC, Qualificação profissional, Geociências, Ensino de geologia

\section{Resumo}

No modelo atual de sociedade capitalista e de auto-sustentabilidade, as geociências desenvolvem imponente importância, principalmente no tocante aos recursos / reservas minerais e aos bens energéticos não renováveis, tais como o hidrocarboneto. Não obstante, esta ciência está intrinsecamente relacionada ao progresso humano, estando assim, associada à construção de barragens, túneis, rodovias, dentre outros, além de ser parâmetro para monitoramento ambiental e hidrogeológico nas interdisciplinaridades inerentes ao tema. O PROEJA-FIC é um programa de ensino de requalificação profissional que foi desenvolvido paulatinamente em parcerias com os Institutos Federais de ensino brasileiros. Sendo assim, o presente trabalho procura apresentar a experiência do projeto em questão no Instituto Federal de Ciência e Tecnologia do Espírito Santo (IFES), Campus Cachoeiro de Itapemirim. As práticas de ensino - aprendizagem se basearam na geologia interativa, procurando atingir o interesse do aluno e o despertar desse indivíduo as observações naturais, usando como ferramentas, aulas expositivas e participativas de "Noções de Geologia", além do uso de material didádico - pedagógico apropriados, com utilização de apostila de linguagem acessível, de conhecimentos básicos em geociências, confeccionada pelos autores e professores em questão, especificamente para esta empreitada. Contudo, passados um semestre de atividades pertinentes ao Proeja, houve um aproveitamento total dos egressos, sendo assim, estes alunos cidadãos, não apresentaram problemas com o conteúdo programático de geologia e, portanto, se motivaram com o curso técnico em Pedreira. 
Key-words: PROEJA - FIC; Professional qualification; Geosciences; Teaching geology

\begin{abstract}
In the current model of capitalist society and self-sustainability, the geosciences develop impressive importance, especially in terms of resources / mineral reserves and nonrenewable energy goods, such as hydrocarbon. Nevertheless, this science is intrinsically related to human progress and are therefore associated with the construction of dams, tunnels, highways, among others, besides being a parameter for monitoring environmental and hydrogeological interdisciplinarity inherent in the subject. The PROEJA-FIC is an educational program of retraining that was gradually developed in partnership with the Federal Institutes of Brazilian education. Therefore, this paper attempts to present the experience of the project in question at the Federal Institute of Science and Technology of the Espirito Santo (IFES), Campus Cachoeiro de Itapemirim. Teaching practices - learning is based on interactive geology, striving to achieve the student's interest and the awakening of the individual natural observations, such as using tools, lectures and participatory "Notions of Geology, and the use of material fertility rate - the appropriate pedagogical, using a book of accessible language, basic knowledge in earth sciences, made by authors and teachers in question, specifically for this task. However, after a semester of activities pertaining to Proeja, there was a total utilization of the graduates, so these students as citizens, had no problems with the syllabus of geology and thus were motivated with the technical school in Quarry.
\end{abstract}

\title{
Introdução
}

O Programa Nacional de Integração da Educação Profissional com a Educação Básica na Modalidade de Educação de Jovens e Adultos PROEJA, teve origem no Decreto $n^{0} 5.478$, de 24/06/2005, encontra-se destinada a proporcionar formação profissional no curso técnico em auxiliar de Pedreira, ofertado desde o primeiro semestre do ano letivo de 2010, pelo Instituto Federal do Espírito Santo (IFES) - Campus de Cachoeiro de Itapemirim, com escolarização simultânea numa escola da rede pública de ensino. Este Proeja, é uma formação inicial e continuada com ensino fundamental $\left(5^{\mathrm{a}}\right.$ a $8^{\mathrm{a}}$ série ou $6^{\circ}$ a $9^{\circ}$ ano), para aqueles que já concluíram a primeira fase do ensino fundamental e, em paralelo, há uma educação profissional técnica, no caso, em auxiliar de pedreira.

$O$ presente trabalho faz um estudo de caso da educação profissionalizante de jovens e adultos na escola técnica Federal do Espírito Santo, destinados a alunos do curso de auxiliar de pedreira, vinculados a mineração, no qual, em demasia, será abordado o perfil do aluno egresso e sua evolução / aperfeiçoamento como aluno e ser humano e quais as 
mudanças e desafios enfrentados pelos docentes para adaptar o currículo e as aulas teóricas / práticas a esta nova perspectiva.

Em virtude de Cachoeiro de Itapemirim, constituir um Arranjo Produtivo Local de Base Mineral (APL Mineral) basicamente representada por abundância de mármores e granitos e, portanto, geodisponibilidade de carbonatos e parte dos trabalhadores não apresentarem qualificação adequada para trabalhar nesse setor extrativo, fez-se necessário e justificável a implementação do Instituto tecnológico em questão, visando qualificar e requalificar jovens em potencial para este mercado, até em razão dos avanços científicos e tecnológicos exigirem cada vez mais trabalhadores aptos a desenvolverem diversas atividades, em simultâneo e como resposta a essas demandas houve a criação do Proeja-Fic para mineração, curso técnico em mineração e o curso superior em engenharia de minas na supracitada instituição de ensino. Entende-se como direito de todos os cidadãos brasileiros o acesso à educação pública, gratuita e de qualidade. Porém, nem sempre esse direito foi concedido à população. Analisando o percurso da educação profissional brasileira, percebe-se que desde o período colonial já existiam práticas educacionais, apesar de serem, de caráter informal e restritos aos engenhos. Porém, posteriormente, surgiram os colégios e as residências dos Jesuítas que passaram a desenvolver a formação profissional (escolas / oficinas), e os ofícios estariam ligados as atividades de carpintaria, de ferraria, de construção de edifícios, embarcações, de pintura, etc. (Silva, et al. 2010).

Com a transferência da Corte Portuguesa para o Brasil em 1808, foi criado um sistema educacional que tinha a finalidade de substituir a lacuna deixada pela expulsão dos Jesuítas do Brasil. Neste período são fundadas instituições de ensino superior, que tinham por finalidade a qualificação de pessoas para o Exército e na Administração do Estado. A educação profissional estava dividida em associações civis e estatais. Em 1824 é promulgada a primeira Constituição Brasileira, no qual propunha uma educação primária gratuita para todos os cidadãos - situação esta, que não veio a se confirmar na prática, em razão desta modalidade atender apenas a elite dominante a época. (adaptado de Sousa, 2009).

Entre 1840 e 1856, são fundadas as casas de educandos artífices, adotando o modelo de aprendizagem de ofícios, surgindo assim, neste período os liceus. Com a implantação da Primeira República a educação profissional ganha um novo perfil, em virtude da adoção de redes escolares, pertencentes aos governos estaduais e federais. Portanto, só com a Constituição de 1934 foi consolidada o dever do Estado em relação ao 
ensino primário, integral, gratuito e de frequência obrigatória, extensiva, inclusive, aos adultos (artigo 150), neste momento se legitima a separação entre o trabalho manual e do intelectual, ensino secundário destinado somente as elites e ensino médio profissionalizante para as classes menos favorecidas. (adaptado de Sousa, 2009).

Durante a década de 1940, o Estado começou a cogitar a educação de jovens e adultos. A luz desse cenário houve o estabelecimento do SENAI (Serviço Nacional de Aprendizagem Industrial), do SENAC (Serviço Nacional de Aprendizagem Comercial) e do SENAR (Serviço Nacional de Aprendizagem Rural).

A Lei $n^{0} 5692 / 71$ trouxe a regulamentação do EJA, e protagonizou uma reforma no ensino médio e fundamental, que instituía a profissionalização compulsória para o ensino secundário, estabelecendo, formalmente, a equiparação entre o curso secundário e os cursos técnicos. Em 1972 dois documentos - Política para o Ensino Supletivo e o Parecer $n^{\circ}$ 699/72- estabeleciam a doutrina do Ensino Supletivo.

O Decreto Federal $n^{\circ}$. 2.208/97 regulamentou a educação profissional, que no Art. $3^{\circ}$, compreende os seguintes níveis:

I - Básico: destinado à qualificação, requalificação e reprofissionalização de trabalhadores, independente de escolaridade prévia;

II - Técnico: destinado à proporcionar habilitação profissional a alunos matriculados ou egressos do ensino médio, devendo ser ministrado na forma estabelecida por este Decreto;

III - Tecnológico: correspondente a cursos de nível superior na área tecnológica, destinados à egressos do ensino médio e técnico.

Os princípios com que se baseiam-se o Proeja-Fic, extraído de (PROEJA. 2006, p.27-28), são os descritos sucintamente abaixo:

I - trata da inclusão de jovens e adultos que não tiveram oportunidade de concluírem a educação básica em sua faixa etária regular, na qual os sistemas educacionais firmam um compromisso de integrá-los a rede, porém primando pela qualidade e assegurando sua permanência nas unidades escolares;

II - consiste na inserção orgânica da modalidade EJA integrada à educação profissional nos sistemas educacionais públicos;

III - ampliação do direito à educação básica, pela universalização do ensino médio; IV- o trabalho como princípio educativo;

$\mathrm{V}$ - a pesquisa como fundamento de formação; 
VI - condições gerenciais, de gênero, de relações étnico-raciais como fundantes da formação humana e dos modos como se produzem as identidades sociais.

\section{Objetivos gerais}

O objeto desse estudo é apresentar a vivência de dois geólogos profissionais com alunos do EJA, enfatizando as aplicações, valorações e o desempenho didático - pedagógico alcançado, bem como, as relações sociais essenciais ao ensino - aprendizagem, neste específico estudo de caso.

\section{Objetivos específicos}

Procurando atingir o interesse do aluno e o despertar desse indivíduo as observações naturais, foco do estudo geológico, a fim de melhor prepará-lo para a comprensão de uma ciência investigativa e integrada acima de tudo com as demais, tais como, os estudos sociais (história e geografia) e as ciências (biologia, química e física), destinando-se a inserí-los no universo da sala-de-aula integrada com o ensino profissionalizante, buscando sempre tratar de assuntos cotidianos e aplicáveis a multidisciplinaridade exigida e praticada. Tendo em vista, esta possibilidade de integração social, científica e tecnológica entre uma escola pública municipal e uma pública federal de ensino profissionalizante, ambos localizados no município de Cachoeiro de Itapemirim, as práticas pedagógicas utilizadas para esta acção educativa significante baseiam-se em:

Aulas práticas e expositivas de Noções de Geologia para o Curso Técnico em Auxiliar de Pedreira, assumindo esta disciplina, como um estudo básico dos principais conceitos referentes as geociências, tais como, minerais e rochas (ígneas, sedimentares e metamórficas), partindo-se do pressuposto de uma ciência geológica participativa e integrativa.

Como alternativas para a disseminação do saber geológico, houve formulações de globos terrestres com as camadas / zonas / extratos da Terra (em núcleo interno, externo, manto inferior, transicional e superior associado com as crostas) em isopor (maquete) e outras ferramentas de auxílio didático.

Uso de minerais (de coleção) e rochas do Laboratório de Mineralogia do Instituto Federal de Ciência e Tecnologia, propiciando aulas práticas, tornando as aulas mais acessíveis, agradáveis e interessantes, ministrando-se 
aulas geodivertidas, a fim de instigar a curiosidade para despertar a observação, base para a metodologia científica.

\section{Metodologia de Trabalho}

As práticas de ensino - aprendizagem adotadas se basearam na geologia interativa, buscando sempre a participação dos alunos e o envolvimento dos mesmos com as ferramentas geológicas (minerais, rochas e fósseis). Contudo, visando melhorar o alcance e o envolvimento dos alunos do EJA com a geologia e a fim de propiciar de fato uma metodologia de ensino participativa, os docentes em questão, confeccionaram uma apostila de linguagem acessível, de conhecimentos básicos em geociências, e acima de tudo, conectada com o público-alvo, ou seja, destinada exclusivamente a este curso em específico. Sendo assim, esta apostila almeja apresentar os conteúdos simplificados e básicos pertinentes a noções de geologia geral destinados ao Programa Nacional de Integração da Educação Profissional com a Educação Básica na Modalidade de Educação de Jovens e Adultos PROEJA - FIC, abordando os conhecimentos essenciais a evolução e compreensão das geociências, de modo elegante e abrangente. A atual proposta e maior pretensão acerca desta empreitada seria a confecção de material didático-pedagógico na busca de melhor assimilação destes conhecimentos aos alunos do EJA, propiciando um processo de ensino aprendizagem de modo prazeroso e significativo, tanto para o corpo discente, quanto para o docente, servindo de estímulo e referência a esta formação inicial continuada (FIC).

Contudo, ressalta-se que a necessidade da elaboração deste material de consulta escolar objetiva-se na reunião e organização dos conteúdos da referida disciplina, apresentando os assuntos em notas de aula, visto que há um grande acúmulo de material bibliográfico que esta disciplina oferece, com a maioria em língua inglesa ou livros técnicos - científicos de uso universitário. Todavia, os materiais e métodos utilizados, além dos já citados, foram os descritos abaixo:

Sensibilização acadêmica, através, inicialmente de um programa de requalificação profissional docente, procurando prevenir futuros infortúnios. Sendo assim, houve um curso para qualificação dos recursos humanos do Instituto de $180 \mathrm{~h}$ de duração intitulado "Curso de Formação Continuada de Técnicos e Docentes para o Proeja-FIC, realizado de agosto a dezembro de 2009, destinado a criação de competências e habilidades necessárias para a qualidade do programa. 
Integração epistemológica, de conteúdos, de metodologias e de prática educativas, tendo como resultado uma interligação teórico-prática, entre o saber e o saber fazer.

Identificação dos possíveis alunos a ingressarem na instituição, lhes conferindo e diagnosticando valores, tais como, problemas sócioeconômicos, deficiências áudio - visuais, a fim de dispor de meios para efetuar uma completa análise de riscos, ou seja, evitar e minimizar desconfortos e evasão escolar.

Formulação de um inventário focado na quantificação dos dados dos alunos, percebendo assim, as características referentes aos discentes a serem controladas, as que deviam ser verificadas, os critérios de aceitação, frequência e as devidas responsabilidades técnicas pertinentes ao corpo docente.

\section{Problemática e Justificativa}

A perspectiva de alunos que buscassem o EJA como uma alternativa de retorno aos estudos, em razão da oferta de 20 vagas oferecidas pela rede federal sempre foi considerável. Isso, em demasia, da ocorrência, no Brasil de desigualdades sociais bastante acentuadas que não foram minimizadas ao longo do desenvolvimento aparente do país. Sendo assim, e considerando que estas desigualdades sócio-culturais-econômicas só se agravaram e progrediram ao longo das últimas décadas, muitos jovens foram obrigados a deixarem os estudos para entrar no mercado de trabalho, para ajudar a sustentar suas respectivas famílias. Sendo assim, o Proeja-Fic, atualmente, apresenta um caráter de humanizar a educação procurando preparar o sujeito tanto para o mercado de trabalho como para vida. Construindo uma visão crítica da sociedade em que ele pertence, formando cidadãos.

Este programa enraíza consigo diversas problemáticas pertinentes ao ensino e aprendizagem discente e a partir de qualificação profissional e pedagógica para o corpo docente, este prezado trabalho procura apresentar o sucesso deste programa na referida instituição de ensino. Curiosamente, explicar geologia para analfabetos funcionais iniciou-se de modo bastante peculiar, em virtude da mistura de emoções pertinentes ao momento, afinal era medo associado com êxtase. O medo decorria do fato do inusitado, que era lecionar geologia para quem não havia ainda nem completado a $5^{\mathrm{a}}$ série do ensino fundamental (antigo ginásio), ou seja, como fazê-los entender um conhecimento sempre tão restrito? A geociência sempre se caracterizou como sendo um conhecimento específico do ramo científico, sendo assim, 
de graduação (nível superior) ou técnico (pós ou integrado ao ensino médio), por exigir, aliás, pré-exigir conhecimentos acerca de outras disciplinas, tais como, química, física, biologia, geografia e matemática. Por outro lado, havia, em contrapartida, a êxtase em ilimitar o conhecimento, tendo em vista, que a geologia nos dias atuais, encontra-se totalmente inserida no dia-a-dia da população como nunca esteve. Portanto, o maior desafio, além da qualificação do corpo docente pata esta empreitada, se deu na motivação desses alunos e na inserção dos mesmos dentro das ciências da Terra, a partir sempre, da participação coletiva, da divisão da disciplina em dois e três professores, tornando-se assim dinâmica e atrativa, visando sempre, mostrar a esse aluno, as diversas interpretações dos processos geológicos. Entretanto, vale ressaltar, que a participação e o interesse desses alunos pela disciplina de noções de geologia foi crescendo constantemente ao longo dos dois semestres em que a referida disciplina foi trabalhada e, a cada aula, seus desempenhos, criatividade, interpretação, crítica, assimilação e conhecimentos progrediram de forma considerável, conforme será apresentada e discutida nos resultados. (adaptado de Nascimento \& Silva, 2010).

\section{Discussões e Resultados}

Analisando o perfil dos alunos da EJA verificou-se como clientela primordial, os sujeitos marginalizados do sistema, ou seja, as pessoas que não tiveram oportunidades de estudarem na época certa, e que, para se enquadrarem ao mundo do trabalho têm que aumentar seu grau de estudos para sair da situação de exclusão em que vivem (Figura 1).

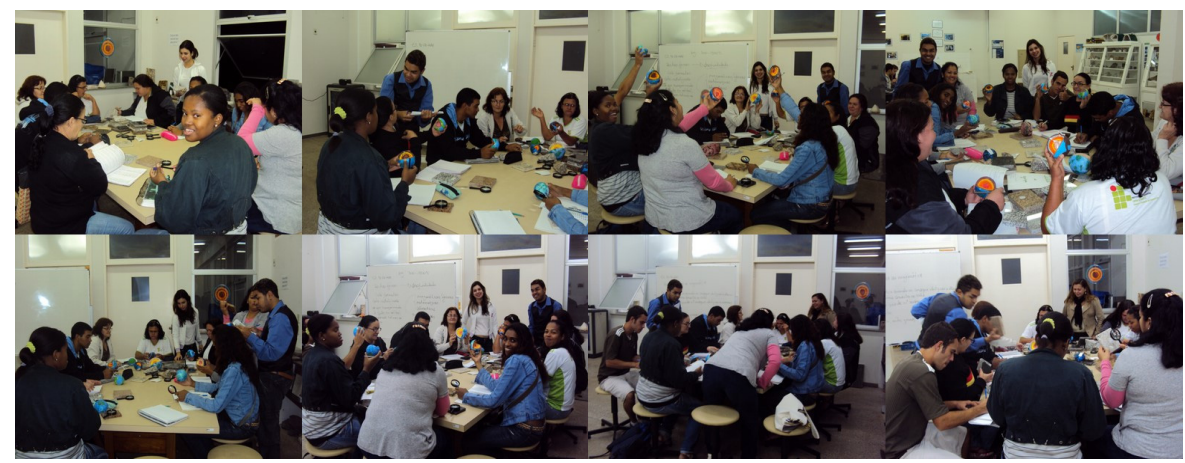

Figura 1. Aula do Proeja-FIC. 
Inicialmente, pressupunha-se na preparação ou requalificação dos docentes para o Proeja-Fic que o público do EJA se trataria, primordialmente, de alunos de idade mais avançada e de grande inserção como trabalhadores que já tivessem inseridos no mercado mineiro. Entretanto, constatou-se a partir de fevereiro de 2010, quando iniciado a primeira, e única turma de Proeja - Fic na mineração, exatamente o contrário. Houve uma forte discrepância de idade, variando dos 18 aos 60 anos, estado civil, portanto em razão da variação de idades, solteiros e casados, relações sociais, apresentando alunos filho de presidiários e que por ventura até se tornaram tal ao longo do curso e basicamente representadas por donas de casas, em busca de qualificação e aprendizagem, reforçando o dito popular: "antes tarde do que nunca". Assim, sendo, esses egressos, não apresentaram muitos problemas em relação ao conteúdo de geociências, até porque a intenção desse curso nunca foi formar futuros geólogos e sim qualificar mão- de - obra apta a mineração. Então, seguindo a temática de aulas interativas, atingiu-se o previsto, ao passo que, os alunos se motivaram com o curso e o retorno pode ser atestado abaixo:

Conclui-se, portanto, que dos 19 alunos regularmente matriculados nesta disciplina, 12 discentes foram devidamente aprovados representando $63 \%$ de aprovações e 7 foram reprovados representando 37\%. Todavia, este resultado nos sugere um aproveitamento total dos egressos, visto que, os alunos que por ventura não atingiram a média, já haviam abandonado o curso por motivos particulares, que incluem, muitas vezes, o fator tempo e cansaço, ao passo que, o curso é noturno, e a maioria, trabalha o dia inteiro e às vezes perdem a motivação de estudarem de segunda a sexta-feira.

Desejando avaliar o ensino - aprendizagem, que relataria o corpo discente x docente, fez-se necessário a confecção de um Plano de Controle, que pode ser entendido como um formulário de registro de verificação do ensino e aprendizagem. Portanto, seria um impresso detentor das características que se desejava controlar, das características a verificar, dos critérios de aceitação, das frequências, das responsabilidades técnicas e do formulário desses registros.

\section{Conclusão}

Ao passo que o semestre evoluía, houve uma transformação de pensamentos e valores perceptíveis a ambos as partes: docentes e discentes, ou seja, esta experiência de ministrar "Noções de Geologia Geral para um público alvo, neste caso, em específico, de PROEJA - FIC, iniciou-se de forma 
desacreditada e por fim, a troca de experiências, diga-se de passagem, de conhecimentos, o inter-relacionamento aluno cidadão e professores despertou um profundo sentimento de realização, em razão do empenho mútuo em acertar, ou pelo menos, oferecer o melhor em prol de um projeto particular, o deles em avançar nos estudos, aprender, conhecer, entender e o nosso em saber conquistá-los, motivá-los, orientá-los, e por fim ensiná-los. Baseando-se nestes fatos e comentários, há de se afirmar que o PROEJA FIC é muito mais do que entrar numa sala de aula, ir rumo ao quadro e escrever ou ligar um projetor (Data Show), pois o primeiro passo é conquistá-los como ser humano, despertá-los ao novo, motivá-los a novas experiências para assim consigamos ensiná-los o proposto.

\section{Bibliografia}

BRASIL. Ministério da Educação. Decreto 5.478 de 24 de junho de 2005 que institui, no âmbito das instituições federais de educação tecnológica, o Programa de Integração da Educação Profissional ao Ensino Médio na Modalidade de Educação de Jovens e Adultos - PROEJA.

BRASIL. Ministério da Educação, Secretaria de Educação Profissional e Tecnológica. Programa de integração da educação profissional ao ensino médio na modalidade de educação de jovens e adultos PROEJA. 2006

BRASIL. Decreto n. 5.154, de 23 de julho de 2004. Regulamenta o $\S 2^{\circ}$ do artigo 36 e os arts. 39 a 41 da Lei n. 9.394, de 20 de dezembro de 1996, que estabelece as diretrizes e bases da educação nacional, e dá outras providências. Diário Oficial da União, Brasília, DF, 24 jul. 2004.

BRASIL. Ministério da Educação. Saberes da Terra: Programa Nacional de Educação de Jovens e Adultos Integrada com Qualificação Social e Profissional para Agricultores (as) Familiares. Brasília. MEC, Out. 2005.

MEC. Programa de integração da educação profissional ao ensino médio na modalidade de educação de jovens e adultos. PROEJA.2006

Nascimento, M. B. ; Silva, P. D. (2010) - Apostila de Noções de Geologia para o Proeja FIC.Instituto Federal do Espírito Santo (IFES). Brasil, 89p.

Silva, P. D., Nascimento, M. B., Wandermurem, C. E. R. (2010) - O conhecimento geológico como uma das ferramentas construtoras das competências e habilidades necessárias a formação do cidadão e sua consciência ambiental. Artigo completo publicado nos Anais do II Congresso Internacional de Tecnologias para o Meio Ambiente, Bento Gonçalves - RS, 8p.

Sousa, C. C. C. (2009) - Educação de Jovens e Adultos e qualificação profissional para alunos trabalhadores da indústria de mineração. Dissertação Lato Sensu. Instituto Federal de Educação Tecnológica de Goiás \& Universidade de Goiás, Goiânia, 59p. 